\title{
ITO/SiO $/$ ITO Structure on a Sapphire Substrate Using the Oxidation of Ultra-Thin Si Films as an Insulating Layer for One-Glass-Solution Capacitive Touch-Screen Panels
}

\author{
Shin Yong Joo ${ }^{1, \dagger}$, Chadrasekhar Loka ${ }^{1,+} \oplus$, Young Woong Jo ${ }^{1}$, Maddipatla Reddyprakash ${ }^{1}$, \\ Sung Whan Moon ${ }^{2}$, YiSik Choi ${ }^{2}$, Seong Eui Lee ${ }^{3}{ }^{-0}$, Gue Serb Cho ${ }^{4}$ and Kee-Sun Lee ${ }^{1, *}$ \\ 1 Department of Advanced Materials Engineering \& Smart Natural Space Research Center, Kongju National \\ University, Cheonan-si 331080, Korea; jooyes@kongju.ac.kr (S.Y.J.); csloka89@gmail.com (C.L.); \\ maleflower@smail.kongju.ac.kr (Y.W.J.); prakashnaidu50@gmail.com (M.R.) \\ 2 Sapphire Technology Co. Ltd., Hwaseong-si 445992, Korea; shmoon@sapphiretek.com (S.W.M.); \\ yschoi@sapphiretek.com (Y.C.) \\ 3 Department of Advanced Materials Engineering, Korea Polytechnic University, 237 Sangidaehak-ro, \\ Siheung-si 406840, Korea; selee@kpu.ac.kr \\ 4 Advanced Process and Materials Group, Korea Institute of Industrial Technology, 156 Gaetbeol-ro, \\ Incheon-si 429450, Gyeonggi-do, Korea; gscho@kitech.re.kr \\ * Correspondence: kslee@kongju.ac.kr \\ $\dagger$ These authors contributed equally to this work.
}

Received: 16 December 2019; Accepted: 1 February 2020; Published: 3 February 2020

\begin{abstract}
The}_{\mathrm{SiO}}$ generated by low-temperature oxidation of ultra-thin metallic silicon (thickness = $50 \mathrm{~nm}$ ) film was evaluated for implementation in one-glass-solution capacitive touch-screen panels (OGS-TSPs) on sapphire-based substrates. Our results show that the silicon films oxidized at $823 \mathrm{~K}$ exhibited the highest visible transmittance about $91 \%$ at $550 \mathrm{~nm}$, compared to $72 \%$ transmittance of the as-deposited silicon films which were deposited at room temperature. Additionally, the annealed films exhibited a more uniform, dense, and smooth surface microstructure than that of the as-deposited Si films. X-ray photoelectron spectroscopy (XPS) results revealed that the low-temperature oxidation of $\mathrm{Si}$ films at $823 \mathrm{~K}$ yielded $\mathrm{SiO}_{2}$. Furthermore, when the insulating $\mathrm{SiO}_{2}$ film obtained by low-temperature oxidation was sandwiched between two indium tin oxide (ITO) layers $\left(\mathrm{ITO} / \mathrm{SiO}_{2} / \mathrm{ITO}\right)$ on a sapphire substrate, the $\mathrm{SiO}_{2}$ film resulted in the dielectric strength of approximately $3 \mathrm{MV} / \mathrm{cm}$. In addition, the highest optical transmittance obtained by the $\mathrm{ITO} / \mathrm{SiO}_{2} / \mathrm{ITO}$ films is about $88.3 \%$. The change in capacitance of the ITO/SiO $2 / I T O$ structure was approximately $3.2 \mathrm{pF}$, which indicates the possibility of implementation in capacitive touch-screen panel devices.
\end{abstract}

Keywords: Thin film: sputtering; $\mathrm{ITO} ; \mathrm{SiO}_{2}$; low-temperature oxidation; touch screen panel; sapphire; transmittance

\section{Introduction}

The high demand for touch-screen panels (TSPs) for implementation in various mobile communication and information devices such as cellular phones, navigation systems, and flat-panel devices continues to increase. Various techniques that employ resistive, capacitive or infrared sensors are implemented in TSP designs. Among these techniques, the capacitive touch-sensitive method is most widely used. In this method, the touch activity is identified by detecting minor changes in the electrical charge generated via human contact with a finger or object. Moreover, because capacitive TSPs enable multi-touch function and multi-tasking, they have become a replacement for conventional 
resistive-type TSPs. Sapphire-based display technology is currently garnering a considerable amount of attention as a means to enhance high-end smartphone devices. The advantages of a sapphire-based display over the conventional glass-based display are good scratch resistance and sensitivity [1]. Despite these advantages, sapphire transparency remains to be a concern, although the transmittance can be optimized in the ultraviolet, infrared, and visible wavelengths by applying a suitable optical coating [2-4]. Touch-type display devices have varying types of multilayer stacks that comprise a complex series of layers of glass (or sapphire), optically clear adhesive (OCA), and indium tin oxide/polyethylene terephthalate (ITO/PET). The deposition of ITO on the PET layer has been a widely employed technique used to fabricate a transparent conducting layer in TSPs [5-8]. Although PET has been confirmed to be effective as an insulating layer, it has been reported to be a cause of the poor crystallinity of the deposited ITO, increased process complexity, and high cost. The low thermal stability of PET limits the heat-treatment temperature of ITO, which thus leads to poor transmittance. Accordingly, the direct deposition of $\mathrm{SiO}_{2}$ on the ITO layer can be employed as an alternative to replacing the PET-based structure, as $\mathrm{SiO}_{2}$ has a relatively high dielectric strength (maximum $10 \mathrm{MV} / \mathrm{cm}$ ) as compared to PET $(150 \sim 200 \mathrm{kV} / \mathrm{cm})$. In general, $\mathrm{SiO}_{2}$ films have been extensively employed in various technological domains $[9,10]$, which can be formed via either physical/chemical deposition or $\mathrm{Si}$ wafer oxidation. The oxidation process possesses the advantage of contamination prevention, and the disadvantage of an elevated temperature process [11,12]. However, since the impregnation of nanovoids in the sputtered $\mathrm{SiO}_{2}$ thin films is inevitable, the densification of the $\mathrm{SiO}_{2}$ film is required to improve the dielectric strength. Silicon films can undergo a positive volume change (volume expansion) during oxidation; this phenomenon is expected to contribute to the densification of $\mathrm{SiO}_{2}$. It is known that the thermal oxidation of bulk silicon such as silicon wafer has been well established for the formation of $\mathrm{SiO}_{2}$ at temperatures between $1073 \mathrm{~K}$ and $1473 \mathrm{~K}$ in an oxygen ambient. However, such an oxidation temperature range cannot be suitable in this study because high-temperature annealing beyond $823 \mathrm{~K}$ can deteriorate the ITO properties because excessive heat affects the structure by creating voids between the grains [13]. Several researchers reported that ITO films exhibited lower resistivity and high visible transmittance $(>80 \%$ at $550 \mathrm{~nm})$ after annealing the films about $673 \mathrm{~K}-823 \mathrm{~K}[14,15]$. Therefore, low-temperature ( $<873 \mathrm{~K}$ ) oxidation of $\mathrm{Si}$ can be appropriate to form the $\mathrm{SiO}_{2}$. In this paper, we report on low-temperature oxidation of $\mathrm{Si}$ film and investigation of its structure and microstructural evolution, and the fabrication of $\mathrm{ITO} / \mathrm{SiO}_{2} / \mathrm{ITO}$ thin-film structure on a sapphire substrate and discuss its potential implementation in one-glass-solution capacitive touch-screen panels (OGS-TSPs).

\section{Materials and Methods}

The silicon thin films were deposited by radio-frequency (RF) magnetron sputtering on sapphire and ITO/sapphire substrates by using a high-purity (99.999\%) silicon target of 2 in. diameter, the sputtering power was fixed at $150 \mathrm{~W}$. A high-purity ITO target (2-in. diameter; $99.99 \%$ purity) containing $10 \mathrm{wt} . \% \mathrm{SnO}_{2}$ was used for the deposition of ITO films with a target power $150 \mathrm{~W}$. Prior to sputter deposition, the vacuum chamber was evacuated to a base pressure below $2.5 \times 10^{-6}$ Torr. An ultra-pure Argon (Ar) gas with a flow rate of 110 and $90 \mathrm{sccm}$ was introduced through a mass-flow controller as a sputtering gas for the deposition of ITO and Si films, respectively. The distance between the target to the substrate was maintained constant at $10 \mathrm{~cm}$, and both the films ITO and Si were deposited at room temperature. The sputter-deposited Si films at room temperature were subsequently oxidized at various temperatures between 723 and $823 \mathrm{~K}$ for four hours in ambient air via rapid thermal annealing (RTA) process and we have investigated the structural, optical, and dielectric properties of $\mathrm{SiO}_{2}$ films prepared via low-temperature oxidation of $\mathrm{Si}$. After the oxidation of Si/ITO films, a top layer ITO was deposited and further annealed for $1 \mathrm{~h}$ to improve the ITO structure. Thus, for the high-quality touch-screen display panel, 50-nm-thick ITO and 70-nm-thick $\mathrm{SiO}_{2}$ films were formed on a sapphire (ITO/SiO $/ 2$ ITO) substrate by using RF magnetron sputtering. The surface microstructure of the $\mathrm{Si}$ and $\mathrm{SiO}_{2}$ were observed via field-emission scanning electron microscopy (FE-SEM, TESCAN MIRAH) (TESCAN MIRA3, Seoul, Korea) and atomic force microscopy (AFM, Park systems, XE-70) 
(Park Systems, Suwon, Korea). A cross-section of the oxidized Si thin film was observed by performing high-resolution transmission electron microscopy (HR-TEM, Tecnai G2 F20) (Thermo Fisher, Hillsboro, OR, USA). The TEM analysis sample was prepared by using a focused ion beam (FIB), a very thin Pt layer was coated over the $\mathrm{SiO}_{2}$ prior to FIB milling because the $\mathrm{SiO}_{2}$ is an insulator. The transmittance spectra were recorded by using a ultraviolet-visible-near infrared (UV-vis-NIR) spectrophotometer (UV-3600, Shimadzu, Kyoto, Japan) Additionally, a chemical analysis of the surface of each film was enabled by X-ray photoelectron spectroscopy (XPS). Lastly, the capacitive characteristics of the TSP were evaluated via the cylindrical rod touch response by employing the conventional direction method for an LC resonance circuit (TMS 1000, FTLAB Inc., Seoul, Korea).

\section{Results and Discussion}

Figure 1 shows the $\mathrm{X}$-ray diffraction pattern $(\mathrm{XRD})$ of the as-deposited and oxidized Si/sapphire films. As can be seen, a very high-intensity peak was observed at $2 \theta=41.6^{\circ}$ corresponding to the sapphire (006) substrate. The Si-related diffraction peaks were not observed in the as-deposited films, which indicate the amorphous nature of the thin films. However, a small diffraction peak appeared around $2 \theta=20.3^{\circ}$ in the annealed films at $823 \mathrm{~K}$ attributed to the polycrystalline $\mathrm{SiO}_{2}$ phase. The diffraction peak was enlarged as shown in the inset of Figure $1 \mathrm{a}$ in the $2 \theta$ range of 20 to $23^{\circ}$. It clearly suggests that the amorphous $\mathrm{Si}$ films were transformed into the polycrystalline $\mathrm{SiO}_{2}$ at low-temperature $(823 \mathrm{~K})$. In contrast, several studies were reported that certain thermally grown $\mathrm{SiO}_{2}$ films consist of crystalline domains [16,17], so the polycrystalline $\mathrm{SiO}_{2}$ phase can be plausibly expected along with the amorphous phase in the annealed films. Nagta et al. reported that the thermally grown crystalline $\mathrm{SiO}_{2}$ by means of thermal oxidation possess high density which is about $4.4 \mathrm{~g} / \mathrm{cm}^{3}$, while the amorphous phase density was about $2.2 \mathrm{~g} / \mathrm{cm}^{3}$ [18]. The cross-sectional TEM image of the Si/sapphire film oxidized at $823 \mathrm{~K}$ is presented in Figure $1 \mathrm{~b}$. The interface between the $\mathrm{SiO}_{2} /$ sapphire was observed to be flat and devoid of any reactions or cavities at the interface, which is an indication of full oxidation and highly dense structure formation via low-temperature oxidation of $\mathrm{Si}$ film i.e. $\mathrm{SiO}_{2}$ formation without any structural distortions induced by substantial volume expansion of Si during the oxidation. Such a flat $\mathrm{SiO}_{2} /$ sapphire interface also represents that the homogeneous oxidation process. In the case of the inhomogeneous oxidation process, the interface roughness could be generally high that attributes the interface distortion energy $[19,20]$.
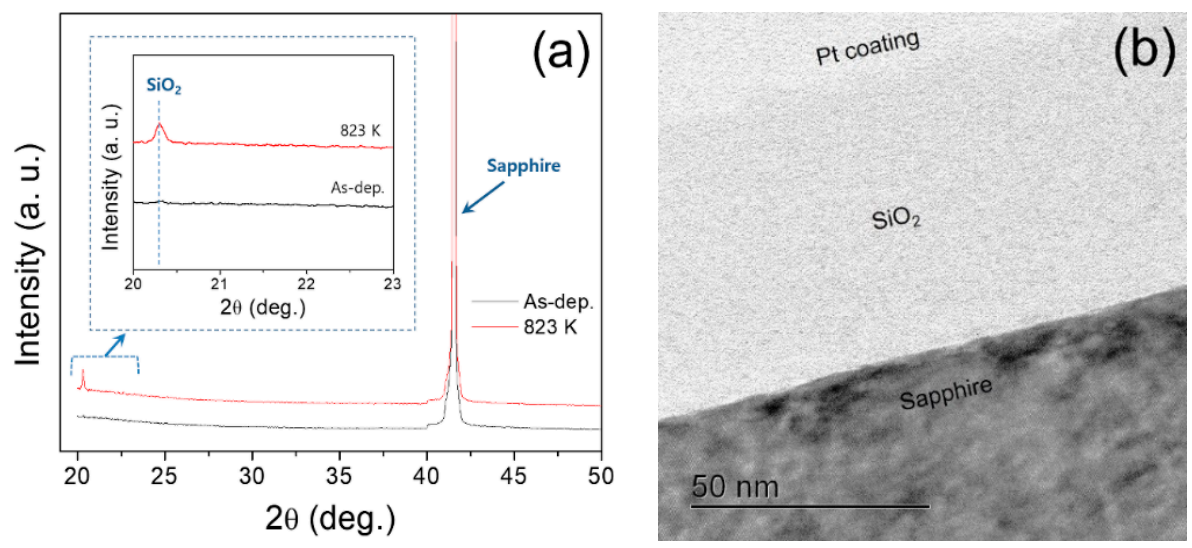

Figure 1. (a) XRD patterns of the as-deposited and oxidized Si/sapphire films; (b) cross-sectional TEM image of the Si/sapphire film oxidized at $823 \mathrm{~K}$.

Oxidation of the Si film was expected to reflect the optical transmittance change. As is shown in Figure 2, the sapphire substrate exhibits an optical transmittance of about $86 \%$ and the as-deposited $\mathrm{Si}$ film exhibit approximately $72 \%$ at the wavelength of $550 \mathrm{~nm}$. However, the transmittance improved as the oxidation temperature was increased. The Si/sapphire film annealed at $823 \mathrm{~K}$ exhibited the 
highest transmittance of approximately $91 \%$. It should be noted that, as the annealing temperature increased, the transmittance approached the transmittance of $\mathrm{SiO}_{2}$; this phenomenon is believed to be due to changes in the optical constants in $\mathrm{SiO}_{\mathrm{x}}$ films. Due to the lower refractive index $\sim 1.45$ of $\mathrm{SiO}_{2}$ film, higher transmittance is generally expected for the $\mathrm{SiO}_{2} /$ sapphire films. In the case of the films oxidized at low-temperatures, there may be lower-valence silicon species that facilitate oxidation of the film. More specifically, oxygen atoms entering into the film increases the thickness of the film, thereby inducing volume expansion and decreasing the refractive index. Lai et al. reported that the transmittance of the films could be described by a single-layer model [21,22], suggesting that the films are homogeneous and that all structural and compositional changes uniformly occur throughout the $\mathrm{SiO}_{\mathrm{x}}$ films under the condition of low-temperature oxidation. In addition, the uniformly structured film can effectively reduce light scattering, and thus enhance transmittance [23]. We also performed simulations to compare the transmittance of the oxidized films by implementing the optical constants of well-defined $\mathrm{SiO}_{2}$ and physical thickness values as inputs into the Essential Macleod optical coating design program [24]. The simulated and experimentally measured transmittance results were found to be in good agreement, indicating that $\mathrm{SiO}_{2}$ phase formation occurred in the absence of the retained Si phase, and that increased surface roughness significantly increased the amount of light that was scattered.

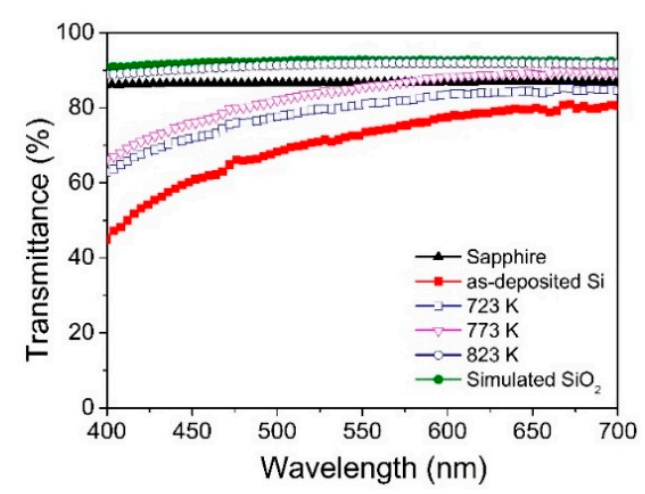

Figure 2. Optical transmittance spectra of the as-deposited and oxidized Si/sapphire films.

As is shown in Figure 3a,b, the as-deposited Si film had a defective surface morphology (as denoted by the arrows and the dotted circle), whereas the oxidized film at $823 \mathrm{~K}$ shows a smooth and uniform surface microstructure comprised of larger grains. AFM was used to observe the microstructural changes; the resulting images are presented in Figure $4 a, b$. The root-mean-square $\left(R_{r m s}\right)$ and peak-to-valley $\left(\mathrm{R}_{\mathrm{pv}}\right)$ roughness values for the as-deposited and oxidized Si films were determined to be 7.74 and $48.67 \mathrm{~nm}$, and 5.87 and $41.2 \mathrm{~nm}$, respectively. As can be seen in Figure 4, the as-deposited films possess a rough surface and localized voids (i.e. nano-sized cavities) indicated with the arrow-lines, which are inevitable during the Si deposition process. In contrast, the oxidized films are shown to have a compact and dense microstructure that is generally comprised of overlapped grains and has no significant trace of voids. It has been reported that $\mathrm{SiO}_{2}$ film growth is dependent on $\mathrm{Si}$ from the $\mathrm{SiO}_{2} / \mathrm{Si}$ interface [25], and the oxidation of amorphous Si film is hindered by the reduced transport of oxygen into the amorphous Si film relative to that occurring in crystalline silicon [26]. Furthermore, assuming that the crystalline $\mathrm{Si}$ was oxidized, the molar volume of $\mathrm{SiO}_{2}$ has been reported to be approximately 2.27 times higher than that of Si crystal [27]; such an increase in volume is believed to overflow into voids or cavities, leading to the formation of a dense $\mathrm{SiO}_{2}$ film (i.e. densification of the film). 

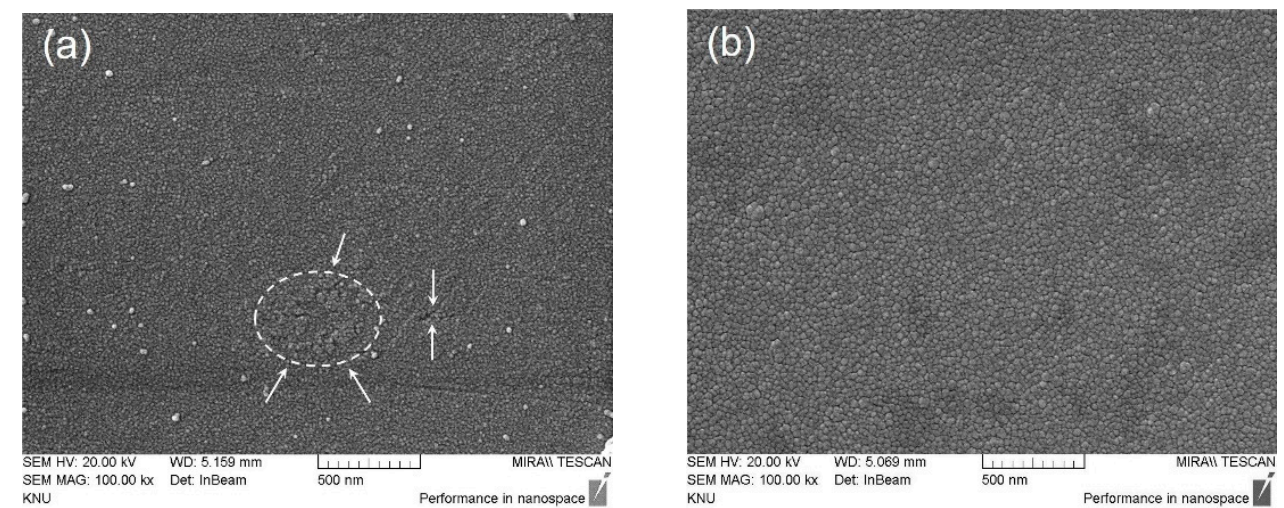

Figure 3. Field-emission scanning electron microscopy (FE-SEM) images of Si/sapphire: (a) as-deposited and (b) oxidized at $823 \mathrm{~K}$.
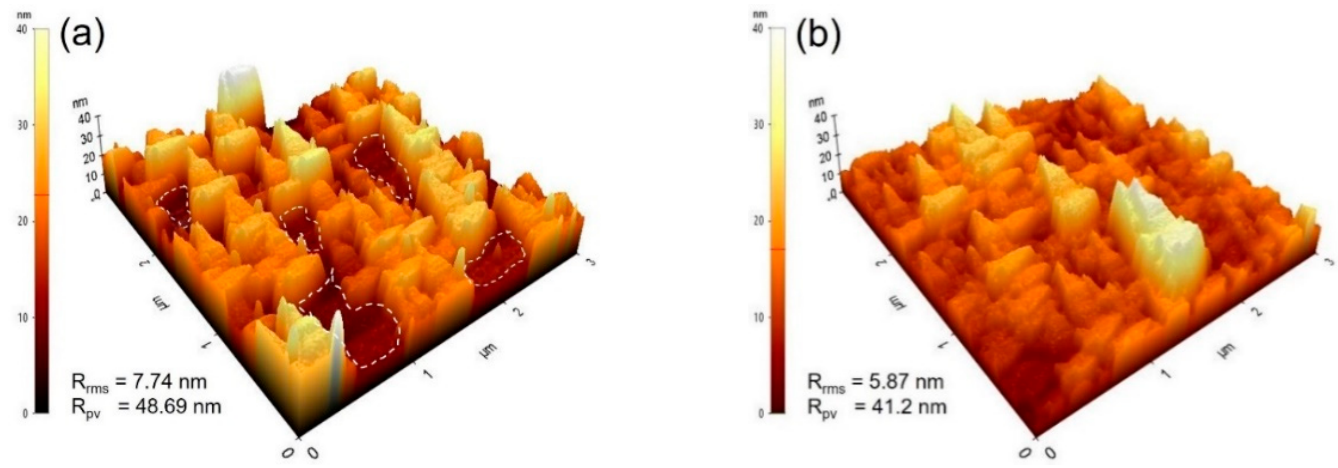

Figure 4. Atomic force microscopy (AFM) images (scan size: $3 \times 3 \mu \mathrm{m}$ ) showing the microstructural surface differences between the (a) as-deposited and (b) oxidized Si/sapphire films at $823 \mathrm{~K}$.

Figure 5 shows the XPS spectra of the surface of the as-deposited and oxidized (at $823 \mathrm{~K}$ ) $\mathrm{Si} / \mathrm{ITO} /$ sapphire thin films; the corresponding $\mathrm{Si}, \mathrm{O}$, and $\mathrm{C}$ peaks have been identified and accordingly labeled. The Si $2 p$ spectra, in addition to the corresponding deconvoluted peaks, are shown in Figure $5 \mathrm{~b}$; the peaks in the as-deposited films at the binding energy 100.92 and $103.74 \mathrm{eV}$ are associated with $\mathrm{Si}^{0}$ of $\mathrm{Si}$ and $\mathrm{Si}^{4+}$ of $\mathrm{Si}-\mathrm{O}$, respectively [28]. For the oxidized films, the $\mathrm{Si} 2 \mathrm{p}$ peaks were slightly shifted to the higher binding energies of 104.4,105.1, and 106.02, which are attributed to the three oxidation states $\mathrm{Si}^{2+}, \mathrm{Si}^{3+}$, and $\mathrm{Si}^{4+}$ of $\mathrm{SiO}_{2}$ and $\mathrm{SiO}_{\mathrm{x}}(\mathrm{x}<2)$, respectively. In Figure $5 \mathrm{c}$, it is clear that the $\mathrm{O} 1 \mathrm{~s}$ deconvoluted peaks at 532.2, 531.6, 533.3, and $532.8 \mathrm{eV}$ are related to the strong $\mathrm{Si}-\mathrm{O}$ bond in $\mathrm{SiO}_{2}$; this finding is consistent with the relevant literature citing that the binding energies range from 532.2 to $533.1 \mathrm{eV}$ [29]. It is known that $\mathrm{SiO}_{2}$ is characterized by higher $\mathrm{Si} 2 \mathrm{p}$ binding energy; it is for this reason that the $\mathrm{Si} 2 \mathrm{p}$ binding energy is shown to increase with increased oxygen content [30,31]. It can also be seen in Figure $5 b$ that the binding energy difference (i.e., chemical shift) in Si $2 p$ between the as-deposited and oxidized films was approximately $3.5 \mathrm{eV}$; this indicates that the unstable Si-O bonds in the as-deposited films tended to form more stable stoichiometric $\mathrm{SiO}_{2}$ during the annealing process. Consequently, in the case of the oxidized $\mathrm{SiO}_{2}$ film, the shift of the $\mathrm{Si} 2 \mathrm{p}$ peak to the higher binding energy is indicative of the strong $\mathrm{Si}-\mathrm{O}$ bond formation in the form of $\mathrm{SiO}_{2}$. 

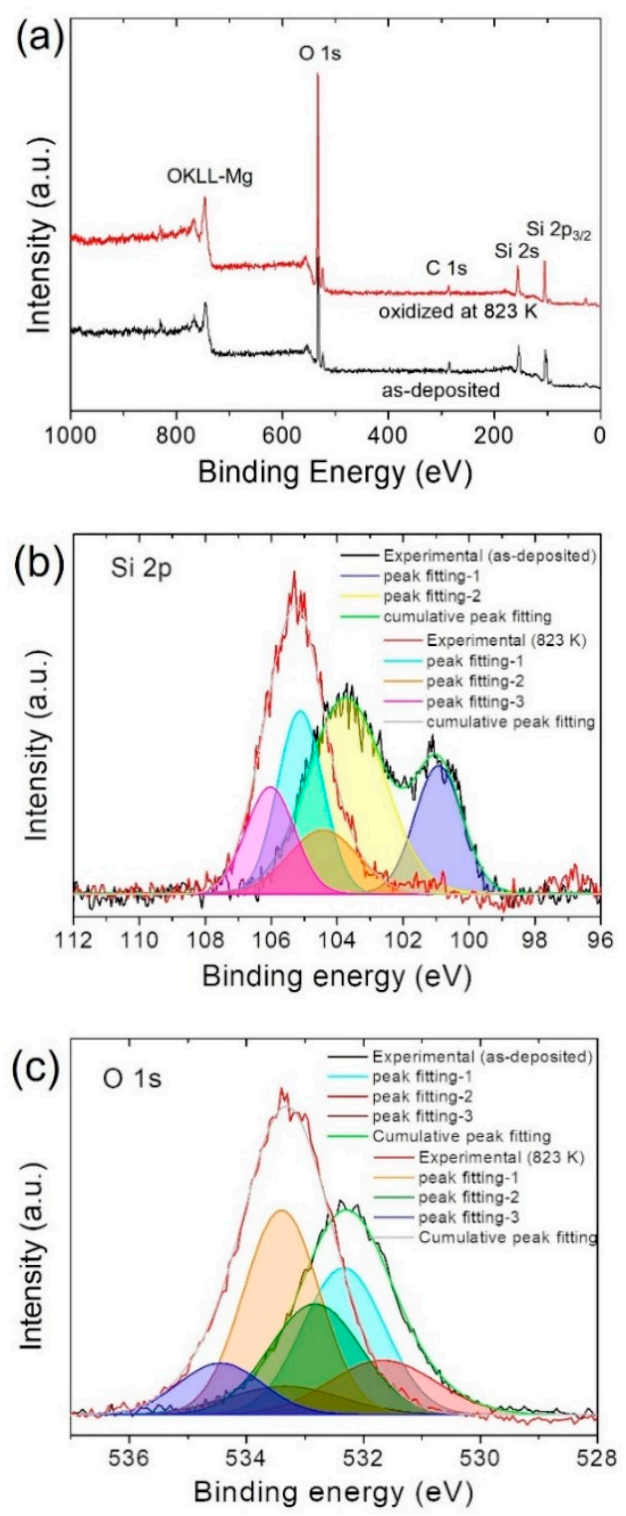

Figure 5. (a) X-ray photoelectron spectroscopy (XPS) survey spectra, (b) Si 2p spectra, and (c) O 1s spectra of the as-deposited and oxidized Si/indium tin oxide (ITO)/sapphire thin films.

Optical transmittance spectra of both two-layer and three-layer structures i.e. Si/ITO/sapphire and $\mathrm{ITO} / \mathrm{SiO}_{2} / \mathrm{ITO} /$ sapphire were shown in Figure 6. The as-deposited $\mathrm{Si} / \mathrm{ITO}$ films showed transmittance of $71.2 \%$ at $550 \mathrm{~nm}$ (Figure 6a). The films were oxidized at low temperatures (723-823 K) to form the $\mathrm{SiO}_{2}$. After the oxidation, the transmittance of the films $\left(\mathrm{SiO}_{2} / \mathrm{ITO}\right)$ was improved to $84.6 \%$. To obtain

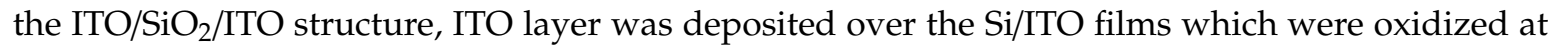
723,773 , and $823 \mathrm{~K}$. Thus, ITO/ $\mathrm{SiO}_{2} / \mathrm{ITO}$ structure was obtained, and it was further annealed by RTA method in air ambient for one hour to improve the top layer ITO crystallinity (Figure 6b). Finally, the ITO/SiO $/ 2$ ITO films annealed at $823 \mathrm{~K}$ exhibited the highest transmittance of $88.3 \%$, which was higher compared to the sapphire substrate (without films). Enhancement in visible light transmittance of the annealed ITO/ $\mathrm{SiO}_{2} / \mathrm{ITO}$ films can be attributed to the ITO film (top layer) structure. Hu et al. reported that the crystalline ITO films obtained by post-annealing of amorphous films exhibited much higher visible transmittance than amorphous films [32]. As a result, the post-annealing treatment of $\mathrm{ITO} / \mathrm{SiO}_{2} / \mathrm{ITO}$ films was effective to enhance the transmittance in the visible region. 

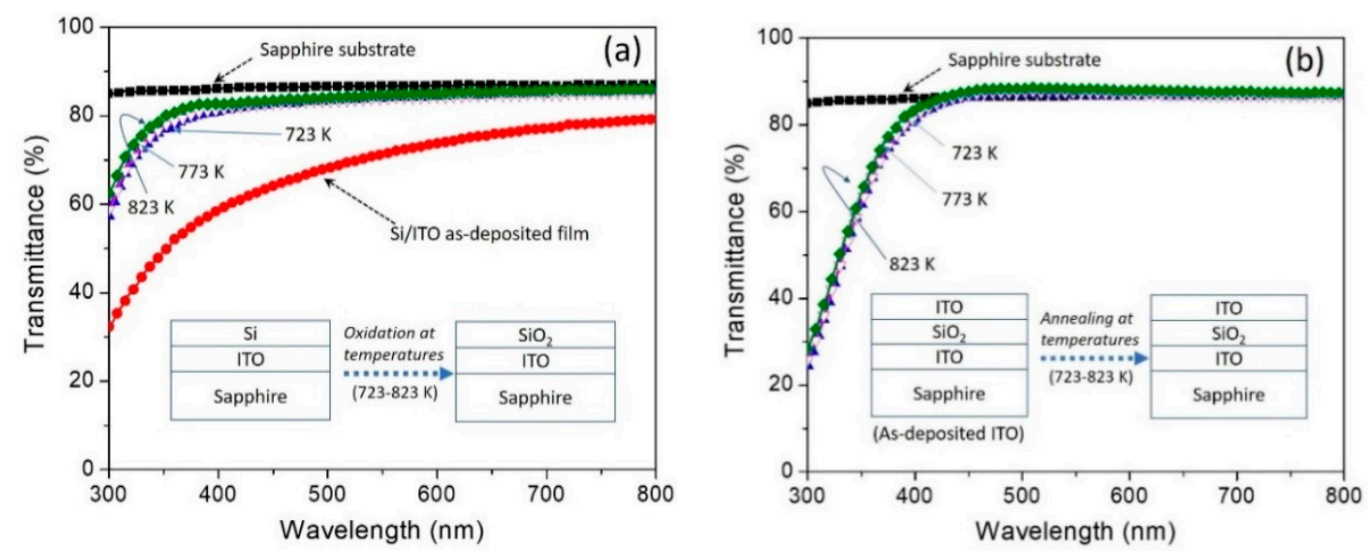

Figure 6. Optical transmittance spectra: (a) as-deposited and oxidized $\mathrm{Si} / \mathrm{ITO} / \mathrm{sapphire,}$ (b) $\mathrm{ITO} / \mathrm{SiO}_{2} / \mathrm{ITO} /$ sapphire films which are annealed for $1 \mathrm{~h}$ after the ITO top layer deposition on $\mathrm{SiO}_{2} / \mathrm{ITO} /$ sapphire.

Finally, a capacitive touch-screen panel was fabricated with the films exhibited the highest transmittance (i.e., ITO/ $/ \mathrm{SiO}_{2} / \mathrm{ITO}$ structure annealed at $823 \mathrm{~K}$ ) by using conducting pads with an individual pattern size of $1 \times 1 \mathrm{~mm}$ to pattern the ITO layer, as is shown in schematic design Figure $7 \mathrm{a}$. There are various shapes and structures of capacitive TSPs based on the method used to form the touch sensor electrodes [33]. Among various methods, a method of forming a touch screen pattern in a low surface of a window and an on-cell TSP method for forming a touch screen pattern in an upper surface of a display effectively increases the display area while reducing the thickness [34]. Schematic is shown in Figure $7 \mathrm{~b}$ represents the cross-sectional view of the ITO/SiO $/ / \mathrm{ITO}$ TSP in which ITO layer of $\mathrm{X}$-axis or X-channel and Y-axis or Y-channel electrodes were indicated. The capacitive characteristics of the fabricated TSP were evaluated by employing the conventional direction method for an LC resonance circuit (TMS 1000, FTLAB Inc. Seoul, Korea) to measure the touch response. In a self-capacitive display, each pad acts as a single electrode with respect to the ground voltage. Each electrode represents a separate touch-coordination pair and must be individually connected to the controller [35,36]. To evaluate touch-sensitivity, the top ITO layer was transformed into conductive pads by photolithography, and copper lines were implemented as the external contacts to the channel electrodes. Additionally, a pressing force of $0.02 \mathrm{MPa}(\sim 500 \mathrm{mN})$ was applied to evaluate the capacitance changes. Figure $8 \mathrm{a}, \mathrm{b}$ show the measured changes in TSP capacitance $[\Delta \mathrm{C}]$ on the sapphire substrate when the channels are switched between the on/off modes, 5 channels were evaluated. When the screen was touched by a conducting cylindrical rod with an approximate diameter of $5 \mathrm{~mm}$, the capacitance of each channel was measured to change by $10 \mathrm{pF}$. Irrespective of the channel number, the change in capacitance was not observed to exceed approximately $4 \mathrm{pF}$; the average change in capacitance for the proposed ITO/SiO $/$ ITO OGS-TSP was measured as approximately $3.2 \mathrm{pF}$. Because the changes in capacitance primarily reflect the dielectric properties of the $\mathrm{SiO}_{2}$ interlayer, the dielectric breakdown strength of the proposed structure was evaluated to better understand the breakdown strength of the $\mathrm{SiO}_{2}$ in ITO/SiO$/ / \mathrm{ITO}$. In general, the change in capacitance that occurs as a finger approaches an intersection for the capacitive TSP is typically approximately $1 \mathrm{pF}$ or less [37]. As compared to the conventional change in capacitance range $\sim 1 \mathrm{pF}$, the $\mathrm{ITO} / \mathrm{SiO}_{2} / \mathrm{ITO}$ structure fabricated on a sapphire substrate exhibited excellent sensitivity with the change in capacitance of $3.2 \mathrm{pF}$. Moreover, its durability and scratch resistance owing to the high degree hardness of the sapphire substrate. Furthermore, the multilayer structure was found to have a dielectric breakdown strength of approximately $3.0 \mathrm{MV} / \mathrm{cm}$, which is enough for TSP applications. This relatively high breakdown strength is related to the quality of the dense $\mathrm{SiO}_{2}$ film. Consequently, in this study, we achieved a high sensitivity OGS-TSP by sandwiching a thin layer of $\mathrm{SiO}_{2}$ formed by low-temperature oxidation of $\mathrm{Si}$ in between the ITO layers. 

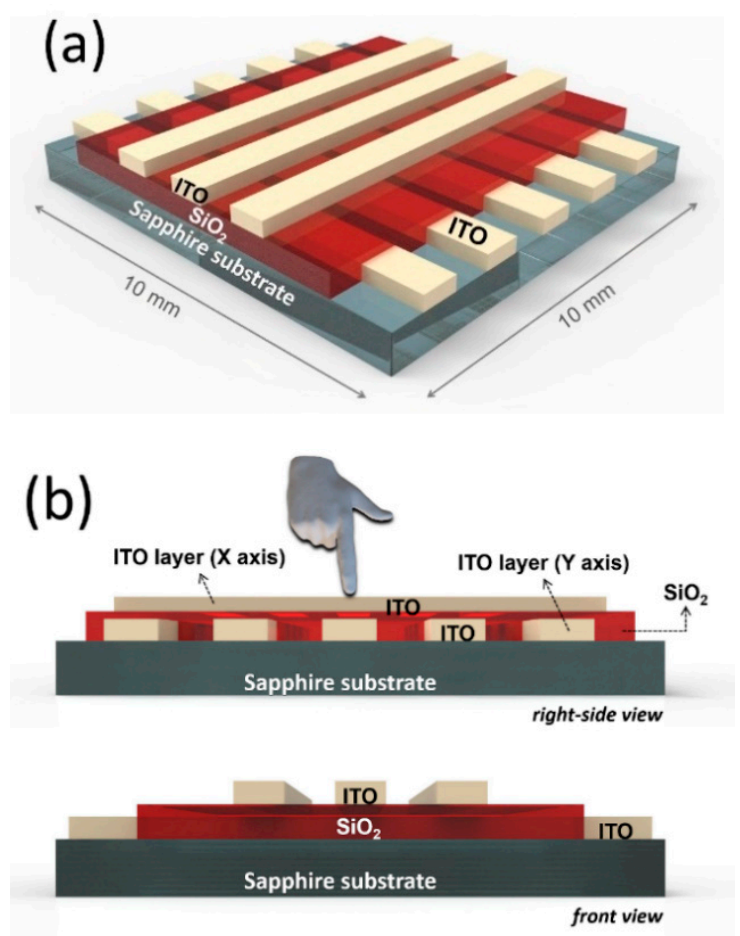

Figure 7. (a) Schematic design of $\mathrm{ITO} / \mathrm{SiO}_{2} / \mathrm{ITO} /$ sapphire capacitive touch-screen panel (TSP) (10 $\mathrm{mm} \times$ $10 \mathrm{~mm}$ ), and (b) cross-section view of the TSP representing the ITO layer (X and Y-axis electrodes) and the $\mathrm{SiO}_{2}$ dielectric layer.
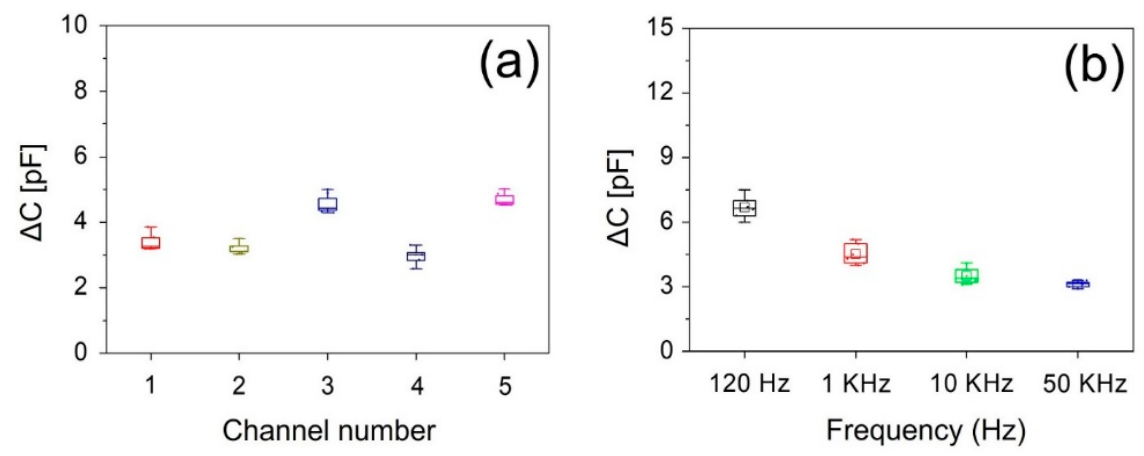

Figure 8. (a) Touch sensor-induced change in capacitance [ $\triangle \mathrm{C}]$ for each channel, and (b) touch sensor-induced change in capacitance $[\triangle \mathrm{C}]$ for various frequencies.

\section{Conclusions}

In this study, a well-defined smooth and dense $\mathrm{SiO}_{2}$ layer was produced by low-temperature oxidation via RTA of the sputter-deposited ultra-thin Si films. The Si films oxidized at $823 \mathrm{~K}$ were found to have high visible transmittance of approximately $91 \%$ at $550 \mathrm{~nm}$ and the optical simulation results were in good agreement with the observed optical transmittance data. The deconvolution of XPS peaks revealed that a well-defined $\mathrm{SiO}_{2}$ formation with strong $\mathrm{Si}-\mathrm{O}$ bonding in the films oxidized at $823 \mathrm{~K}$. In order to investigate the potential application of $\mathrm{SiO}_{2}$ generated by low-temperature oxidation of Si/ITO

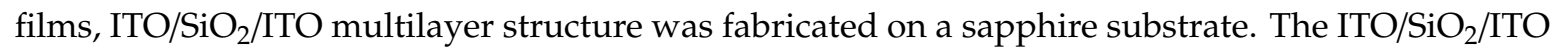
films annealed at $823 \mathrm{~K}$ exhibited the highest transmittance $\sim 88.3 \%$ in the visible region. Moreover, the proposed ITO/ $\mathrm{SiO}_{2} / \mathrm{ITO}$ multilayer films exhibited a relatively high dielectric breakdown strength of approximately $3 \mathrm{MV} / \mathrm{cm}$ owing to the densely formed $\mathrm{SiO}_{2}$ films. The touch-sensitive capacitance results revealed that the proposed design, which entails sandwiching a low-temperature-oxidized 
$\mathrm{SiO}_{2}$ film in between the ITO layers on a sapphire substrate, has the potential to be implemented in capacitive TSP devices to realize high dielectric breakdown strength.

Author Contributions: Conceptualization, S.Y.J., C.L. and K.-S.L.; methodology, S.Y.J. and C.L.; software, C.L.; validation, Y.W.J., M.R., S.W.M., Y.C., S.E.L and G.S.C.; formal analysis, S.Y.J. and C.L.; investigation, S.Y.J.; data curation, C.L.; writing-original draft preparation, S.Y.J. and C.L.; writing-review and editing, S.E.L. and K.S.L.; visualization, C.L.; supervision, K.-S.L. All authors have read and agreed to the published version of the manuscript.

Funding: This research was funded by Priority Research Centers Program through the National Research Foundation of Korea (NRF), Ministry of Education (2019R1A6A1A03032988). This research was funded by International Science and Business Belt Program through the Ministry of Science and ICT (2015-DD-RD-0068-05).

Acknowledgments: This work was supported by the Priority Research Centers Program through the National Research Foundation of Korea (NRF) funded by the Ministry of Education (2019R1A6A1A03032988). This research was supported by the International Science and Business Belt Program through the Ministry of Science and ICT (2015-DD-RD-0068-05).

Conflicts of Interest: The authors declare no conflict of interest.

\section{References}

1. Dobrovinskaya:, E.R.; Lytvynov, L.A.; Pishchik, V. Properties of Sapphire; Springer: Boston, MA, USA, 2009.

2. Loka, C.; Lee, K.; Moon, S.W.; Choi, Y.; Lee, K.S. Enhanced transmittance of sapphire by silicon oxynitride thin films annealed at high temperatures. Mater. Lett. 2018, 213, 354-357. [CrossRef]

3. Kim, S.; Cho, J.; Char, K. Thermally stable antireflective coatings based on nanoporous organosilicate thin films. Langmuir 2007, 23, 6737-6743. [CrossRef] [PubMed]

4. Yancey, S.E.; Zhong, W.; Heflin, J.R.; Ritter, A.L. The influence of void space on antireflection coatings of silica nanoparticle self-assembled films. J. Appl. Phys. 2006, 99. [CrossRef]

5. Ahn, M.H.; Cho, E.S.; Kwon, S.J. Characteristics of ITO-resistive touch film deposited on a PET substrate by in-line DC magnetron sputtering. Vacuum 2014, 101, 221-227. [CrossRef]

6. Lee, W.J.; Fang, Y.K.; Ho, J.J.; Chen, C.Y.; Tsai, R.Y.; Huang, D.; Ho, F.C.; Chou, H.W.; Chen, C.C. Pulsed-magnetron-sputtered low-temperature indium tin oxide films for flat-panel display applications. J. Electron. Mater. 2002, 31, 129-135. [CrossRef]

7. Qin, H.; Dong, J.; Lee, Y.S. Fabrication and electrical characterization of multi-layer capacitive touch sensors on flexible substrates by additive e-jet printing. J. Manuf. Process. 2017, 28, 479-485. [CrossRef]

8. Xia, N.; Gerhardt, R.A. Fabrication and characterization of highly transparent and conductive indium tin oxide films made with different solution-based methods. Mater. Res. Express 2016, 3, 1-11. [CrossRef]

9. Kingon, A.I.; Maria, J.P.; Streiffer, S.K. Alternative dielectrics to silicon dioxide for memory and logic devices. Nature 2000, 406, 1032-1038. [CrossRef]

10. Ho, W.J.; Lin, J.C.; Liu, J.J.; Bai, W.B.; Shiao, H.P. Electrical and Optical Characterization of Sputtered Silicon Dioxide, Indium Tin Oxide, and Silicon Dioxide/Indium Tin Oxide Antireflection Coating on Single-Junction GaAs Solar Cells. Materials 2017, 10, 700. [CrossRef]

11. Mur, P.; Semeria, M.N.; Olivier, M.; Papon, A.M.; Leroux, C.; Reimbold, G.; Gentile, P.; Magnea, N.; Baron, T.; Clerc, R.; et al. Ultra-thin oxides grown on silicon $\left(\begin{array}{lll}1 & 0 & 0\end{array}\right)$ by rapid thermal oxidation for CMOS and advanced devices. Appl. Surf. Sci. 2001, 175-176, 726-733. [CrossRef]

12. Lerch, W.; Roters, G.; Münzinger, P.; Mader, R.; Ostermeir, R. Wet rapid thermal oxidation of silicon with a pyrogenic system. Mater. Sci. Eng. B 1998, B54, 153-160. [CrossRef]

13. Ahmed, N.M.; Sabah, F.A.; Abdulgafour, H.I.; Alsadig, A.; Sulieman, A.; Alkhoaryef, M. The effect of post annealing temperature on grain size of indium-tin-oxide for optical and electrical properties improvement. Results Phys. 2019, 13, 102159. [CrossRef]

14. Song, S.; Yang, T.; Liu, J.; Xin, Y.; Li, Y.; Han, S. Rapid thermal annealing of ITO films. Appl. Surf. Sci. 2011, 257, 7061-7064. [CrossRef]

15. Park, J.H.; Buurma, C.; Sivananthan, S.; Kodama, R.; Gao, W.; Gessert, T.A. The effect of post-annealing on Indium Tin Oxide thin films by magnetron sputtering method. Appl. Surf. Sci. 2014, 307, 388-392. [CrossRef]

16. Munkholm, A.; Brennan, S. Ordering in Thermally Oxidized Silicon. Phys. Rev. Lett. 2004, 93. [CrossRef] [PubMed] 
17. Iida, Y.; Shimura, T.; Harada, J.; Samata, S.; Matsushita, Y. A structural study of the thermally oxidized Si(001) wafer by X-ray CTR scattering. Surf. Sci. 1991, 258, 235. [CrossRef]

18. Nagata, K.; Ogura, A.; Hirosawa, I.; Suwa, T.; Teramoto, A.; Hattori, T.; Ohmi, T. Structural Analyses of Thin $\mathrm{SiO}_{2}$ Films Formed by Thermal Oxidation of Atomically Flat Si Surface by Using Synchrotron Radiation X-Ray Characterization. ECS J. Solid State Sci. Technol. 2015, 4, N96. [CrossRef]

19. Tokuda, N.; Murata, M.; Hojo, D.; Yamabe, K. SiO 2 Surface and SiO2/Si Interface Topography Change by Thermal Oxidation. Jpn. J. Appl. Phys. 2001, 40, 4763. [CrossRef]

20. Hasunuma, R.; Okamoto, J.; Tokuda, N.; Yamabe, K. Nonuniformity in Ultrathin $\mathrm{SiO}_{2}$ on $\mathrm{Si}(111)$ Characterized by Conductive Atomic Force Microscopy. Jpn. J. Appl. Phys. 2004, 43, 7861. [CrossRef]

21. Lai, F.; Li, M.; Wang, H.; Jiang, Y.; Song, Y. Effect of oxygen flow rate on the properties of $\mathrm{SiO}_{\mathrm{x}}$ films deposited by reactive magnetron sputtering. Chin. Opt. Lett. 2005, 3, 490-493.

22. Huang, F.; Song, Q.; Li, M.; Xie, B.; Wang, H.; Jiang, Y.; Song, Y. Influences of annealing temperature on the optical properties of $\mathrm{SiOx}$ thin film prepared by reactive magnetron sputtering. Appl. Surf. Sci. 2008, 255, 2006-2011. [CrossRef]

23. Ferriu, F.; Devine, R.A.B. Densification and porosity in low-temperature-deposited oxide. J. Non-Cryst. Solids 1989, 113, 100-102. [CrossRef]

24. MacLeod, A.; Clark, C. The Essential MacLeod Version 9. 6. 415; Thin Film Center Inc.: Tucson, AZ, USA, 2012; pp. 85716-95227.

25. Kageshima, H.; Shiraishi, K. First-principles study of oxide growth on si(100) surfaces and at $\mathrm{SiO} / \mathrm{si}(100)$ interfaces. Phys. Rev. Lett. 1998, 81, 5936-5939. [CrossRef]

26. Silva, A.G.; Pedersen, K.; Li, Z.S.; Morgen, P. Oxidation of the surface of a thin amorphous silicon film. Thin Solid Films 2011, 520, 697-699. [CrossRef]

27. Chalmers, A. Physical Metallurgy, 1st ed.; John Wiley \& Sons Inc: Hoboken, NJ, USA, 1959.

28. Barr, T.L. An XPS study of Si as it occurs in adsorbents, catalysts, and thin films. Appl. Surf. Sci. 1983, 15, 1-35. [CrossRef]

29. Khassin, A.A.; Yurieva, T.M.; Demeshkina, M.P.; Kustova, G.N.; Itenberg, I.S.; Kaichev, V.V.; Plyasova, L.M.; Anufrienko, V.F.; Molina, I.Y.; Larina, T.V.; et al. Characterization of the nickel-amesite-chlorite-vermiculite system. Part I. Silicon binding in Ni-Mg-Al phylloaluminosilicates. Phys. Chem. Chem. Phys. 2003, 5, 4025-4031. [CrossRef]

30. Alfonsetti, R.; Lozzi, L.; Passacantando, M.; Picozzi, P.; Santucci, S. XPS studies on SiOx thin films. Appl. Surf. Sci. 1993, 70, 222-225. [CrossRef]

31. Wang, L.; Jiang, Y.; Jiang, C.; Liu, H.; Ji, Y.; Zhang, F.; Fan, R.; Chen, D. Effect of oxygen flow rate on microstructure properties of $\mathrm{SiO}_{2}$ thin films prepared by ion beam sputtering. J. Non. Cryst. Solids 2018, 482, 203-207. [CrossRef]

32. Hu, Y.; Diao, X.; Wang, C.; Hao, W.; Wang, T. Effects of heat treatment on properties of ITO films prepared by rf magnetron sputtering. Vacuum 2004, 75, 183-188. [CrossRef]

33. Lee, C.; Park, J.K.; Piao, C.; Seo, H.; Choi, J.; Chun, J. Mutual Capacitive Sensing Touch Screen Controller for Ultrathin Display with Extended Signal Passband Using Negative Capacitance. Sensors 2018, $18,3637$. [CrossRef]

34. Heo, H.D.; Kim, D.S.; Eom, S.Y. On-Cell TSP Display Device. U.S. Patent Application No. 13,214,678, 1 March 2012.

35. Barrett, G.; Omote, R. Projected-Capacitive Touch Technology. Inf. Disp. 2010, 26, 16-21. [CrossRef]

36. Hotelling, S.; Strickon, J.A.; Huppi, B.Q. Multipoint touchscreen. U.S. Patent 0097991 A1, 11 May 2006.

37. Phares, R.; Fihn, M. Introduction to Touchscreen Technologies in Handbook of Visual Display Technology; Springer: Berlin, Germany, 2012; pp. 935-974.

(C) 2020 by the authors. Licensee MDPI, Basel, Switzerland. This article is an open access article distributed under the terms and conditions of the Creative Commons Attribution (CC BY) license (http://creativecommons.org/licenses/by/4.0/). 